\title{
Структура и электрические свойства тонких пленок $\left(\mathrm{ZnO} / \mathrm{SiO}_{2}\right)_{25}$
}

\author{
(C) М.Н. Волочаев ${ }^{1}$, Ю.Е. Калинин ${ }^{2}$, М.А. Каширин ${ }^{2}$, В.А. Макагонов ${ }^{2}$, \\ С.Ю. Панков ${ }^{2}$, В.В. Бассараб ${ }^{2}$ \\ ${ }^{1}$ Институт фризики им. Л.В. Киренского Сибирского отделения Российской академии наук, \\ 660036 Красноярск, Россия \\ ${ }^{2}$ Воронежский государственный технический университет, \\ 394026 Воронеж, Россия \\ E-mail: vlad_makagonov@mail.ru \\ Поступила в Редакцию 4 июня 2019 г. \\ В окончательной редакции 25 июня 2019 г. \\ Принята к публикации 25 июня 2019 г.
}

В едином процессе напыления были синтезированы многослойные тонкопленочные образцы $\left(\mathrm{ZnO} / \mathrm{SiO}_{2}\right)_{25}$, состоящие из слоев нанокристаллического $\mathrm{ZnO}$ и прослоек аморфного $\mathrm{SiO}_{2}$, с толщиной бислоя от 6 до 10 нм. Из анализа температурных зависимостей удельного электрического сопротивления тонких пленок $\left(\mathrm{ZnO} / \mathrm{SiO}_{2}\right)_{25}$ было установлено, что в диапазоне температур 77-300 K наблюдается последовательная смена доминирующего механизма проводимости от прыжкового с переменной длиной прыжка в узкой полосе энергий вблизи уровня Ферми при температурах $77-250 \mathrm{~K}$ к термоактивированной примесной проводимости при температурах, близких к комнатной. По результатам исследования температурных зависимостей электрического сопротивления сделаны оценки эффективной плотности локализованных состояний на уровне Ферми и значений энергии активации примесных уровней. Исследовано влияние термической обработки на структуру и электрические свойства синтезированных пленок. Было обнаружено, что в тонкопленочных системах $\left(\mathrm{ZnO} / \mathrm{SiO}_{2}\right)_{25}$ при температурах $580-600^{\circ} \mathrm{C}$ происходит химическое взаимодействие между слоями $\mathrm{ZnO}$ и $\mathrm{SiO}_{2}$, сопровождающееся разрушением многослойной структуры и появлением химического соединения $\mathrm{Zn}_{2} \mathrm{SiO}_{4}$ с тетрагональной структурой (пространственная группа I-42d).

Ключевые слова: тонкие пленки, многослойные структуры, оксидные полупроводники, прыжковая проводимость, термическая стабильность.

DOI: 10.21883/FTP.2019.11.48445.9185

\section{1. Введение}

Тонкие пленки оксида цинка обладают важным для практического применения сочетанием свойств - прозрачностью в видимом диапазоне электромагнитного излучения и небольшим электрическим сопротивлением, что обеспечивается большим значением ширины запрещенной зоны и получением нестехиометрических составов либо путем введения соответствующих легирующих элементов соответственно [1-3]. Возможность практического применения тонких пленок $\mathrm{ZnO}$ зависит не только от их оптических и электрических свойств: эти параметры должны сочетаться со стабильностью к воздействиям окружающей среды, стойкостью к истиранию, малой работой выхода электронов, совместимостью с подложкой и другими требованиями, накладываемыми на тонкие пленки прозрачных полупроводников в зависимости от области их применения.

Свойства оксида цинка и соединений на его основе определяются в первую очередь наличием кислородных вакансий, числом которых можно управлять, либо вводя кислород в процессе синтеза материала, либо проводя термическую обработку полученных пленок в окислительной атмосфере [4]. Во вторую очередь необходимостью контролировать структурное состояние (аморфное или кристаллическое), что достигается путем введения специальных элементов - аморфизаторов. К ним относятся атомы Sn, Si или других легирующих элементов [4].

Объединить два этих подхода можно при использовании технологии совместного вакуумного напыления. Так, в работе [5] при помощи высокочастотного (ВЧ) магнетронного распыления мишеней $\mathrm{ZnO}$ и $\mathrm{SiO}_{2}$ были получены тонкие пленки $\left(\mathrm{SiO}_{2}\right)_{x}(\mathrm{ZnO})_{100-x}(\mathrm{SZO})$ с различным содержанием $x=2,3,4,5$ масс $\% \mathrm{Si}$. Было обнаружено, что наименьшее удельное сопротивление $4.5 \cdot 10^{-3} \mathrm{OM} \cdot$ см достигается в пленке с $x=2 \mathrm{мacc} \% \mathrm{Si}$. Эта пленка демонстрировала высокую оптическую прозрачность $\sim 85 \%$ в видимом диапазоне длин волн, что обеспечивалось шириной запрещенной зоны более 3.4 эВ и высоким показателем преломления 2.1. Удельное электрическое сопротивление этой пленки после отжига в течение 30 мин при $300^{\circ} \mathrm{C}$ в вакууме достигало $10^{-3} \mathrm{OM} \cdot \mathrm{cm}$, что сопоставимо с пленками оксида индия, легированного оловом (ITO) [6]. Следовательно, пленки SZO могут потенциально применяться в качестве альтернативных пленочных материалов прозрачной электроники.

В последние годы в качестве каналов тонкопленочных транзисторов (TFT) предложено использовать многослойные гетероструктуры, состоящие из слоев оксидных полупроводников [7-9]. Интерес к таким структурам связан с тем, что, несмотря на активное использова- 
ние в качестве каналов TFT широкозонных аморфных оксидных полупроводников и твердых растворов на их основе, нестабильность и недолговечность рабочих характеристик в однослойных каналах ТFT, возникающая под влиянием различных условий (температура, напряжение смещения, освещенность), является одной из ключевых проблем практического применения прозрачных электропроводящих оксидов. Причиной такой нестабильности являются кислородные вакансии. В то же время известно, что носители заряда в прозрачных оксидных полупроводниках обеспечиваются дефектами, связанными с кислородом, и, таким образом, плотность вакансий кислорода определяет электрические свойства оксидных полупроводников. Таким образом, возникает ситуация, когда приходится выбирать между стабильностью работы и ухудшением рабочих характеристик. Кроме того, применяемые в настоящее время материалы каналов ТFT не отвечают предъявляемым к ним требованиям, связанным со скоростью работы, временем переключения и подвижностью носителей заряда.

Выходом из сложившейся ситуации является изготовление двухслойных и многослойных канальных структур TFТ-устройства с высокой подвижностью носителей заряда и высокой стабильностью рабочих характеристик. Так, авторами [10] был получен материал канала прозрачного TFT путем осаждения слоев $\mathrm{ZnO}$ и $\mathrm{Al}_{2} \mathrm{O}_{3}$ методом атомно-слоевого осаждения (ACO). Было проведено сравнение характеристик транзистора в случае, когда материалом канала являлся чистый $\mathrm{ZnO}$ и многослойная структура $\mathrm{ZnO} / \mathrm{Al}_{2} \mathrm{O}_{3}$. Было установлено, что многослойная структура $\mathrm{ZnO} / \mathrm{Al}_{2} \mathrm{O}_{3}$ в качестве канала TFT общей толщиной $\sim 22$ нм демонстрирует электрические свойства, улучшенные в сравнении с ZnO. Причинами такого улучшения авторы работы считают вызванный введением прослоек $\mathrm{Al}_{2} \mathrm{O}_{3}$ ориентированный рост кристаллитов $\mathrm{ZnO}$ с осью $c$, направленной перпендикулярно фронту роста многослойной структуры, что сопровождается увеличением подвижности носителей заряда в слоях $\mathrm{ZnO}$.

В данной работе рассмотрены структура и физические свойства тонких пленок многослойных тонкопленочных систем $\left(\mathrm{ZnO} / \mathrm{SiO}_{2}\right)_{25}$ (цифрой 25 обозначено количество бислоев $\mathrm{ZnO} / \mathrm{SiO}_{2}$ ), а также влияние термообработки на стабильность многослойной структуры и ее электрических свойств.

\section{2. Образцы и методика әксперимента}

Тонкие пленки $\left(\mathrm{ZnO} / \mathrm{SiO}_{2}\right)_{25}$ были получены методом ионно-лучевого распыления керамических мишеней $\mathrm{ZnO}$ и $\mathrm{SiO}_{2}$ в атмосфере аргона с чистотой 99.998\% при давлении $7 \cdot 10^{-4}$ Торр по методике, описанной в [11]. Мишени были закреплены на водоохлаждаемых медных основаниях и размещены в разных положениях распыления в вакуумной камере. Для того чтобы осуществить послойное осаждение, подложка перемещалась из одного положения распыления в другое путем вращения подложкодержателя вокруг оси напылительной камеры. Осаждение велось на подложки из монокристаллического кремния с кристаллографической ориентацией (100) для исследования структуры и ситалла для исследования электрофизических свойств. В процессе напыления поддерживалась комнатная температура подложек. Для получения различных толщин слоев $\mathrm{ZnO}$ и $\mathrm{SiO}_{2}$ в ходе единого процесса напыления между мишенью и держателем подложки был установлен $V$-образный экран. Скорость вращения подложкодержателя для пленок $\left(\mathrm{ZnO} / \mathrm{SiO}_{2}\right)_{25}$. составляла 0.13 об/мин.

Для оценки толщины слоев осуществлялось предварительное напыление отдельных пленок $\mathrm{ZnO}$ и $\mathrm{SiO}_{2}$ с подобранными ранее для напыления многослойной структуры параметрами процесса. Измерение толщины полученных пленок проводилось с помощью оптического интерферометра МИИ-4. Зная число оборотов подложкодержателя, рассчитывалась толщина пленки, полученная за одно прохождение подложкой зоны нанесения материала, т.е. толщина монослоя одного из напыляемых оксидов. Аналогичным образом определялась толщина монослоя второй фазы многослойной структуры.

Число оборотов держателя подложки задавало количество бислоев многослойной пленки $\left(\mathrm{ZnO} / \mathrm{SiO}_{2}\right)_{25}$. Согласно описанной методике было получено 25 бислоев. Значения толщины бислоев изменялись от 7.4 до $9.6 \mathrm{Hм}$, при этом с ростом толщины бислоя толщина прослоек $\mathrm{ZnO}$ увеличивались с 3.9 до $6.3 \mathrm{Hм}$, а для прослойки $\mathrm{SiO}_{2}$ - уменьшалась с 3.5 до $3.2 \mathrm{Hм}$. Структуру полученных пленок исследовали методами дифракции рентгеновских лучей на дифрактометpe Bruker D2 Phaser $\left(\lambda_{\mathrm{Cu} K_{\alpha} 1}=1.54 \AA\right)$ с применением программного обеспечения DIFFRAC.EVA 3.0 с базой данных ICDD PDF Release 2012. Исследования поперечного сечения образцов методом просвечивающей электронной микроскопии (ПЭМ) проводились на ПЭМ Hitachi HT7700 (ускоряющее напряжение 100 кэВ, $W$-источник). Образцы были подготовлены при помощи системы фокусируемого ионного пучка ФИП (FIB) (однолучевой FIB, Hitachi FB2100) при ускоряющем напряжении 40 кВ и дополнительной финишной полировке ионами $\mathrm{Ar}^{+}$c низкой энергией. Толщина подготовленных таким способом образцов составила $\sim 30-40 \mathrm{Hм}$. Для защиты от травления пучком ионов $\mathrm{Ga}^{+}$поверхность тонких пленок $\left(\mathrm{ZnO} / \mathrm{SiO}_{2}\right)_{25}$ покрывалась слоем напыленного термическим способом слоя аморфного $\mathrm{SiO}$.

Зависимости удельного электрического сопротивления в зависимости от толщины бислоя и температуры были измерены двухзондовым методом на постоянном токе при помощи универсального цифрового мультиметpa B7-78/1. Относительная погрешность измерения электрического сопротивления исследуемых тонких пленок не превышала $2 \%$. 

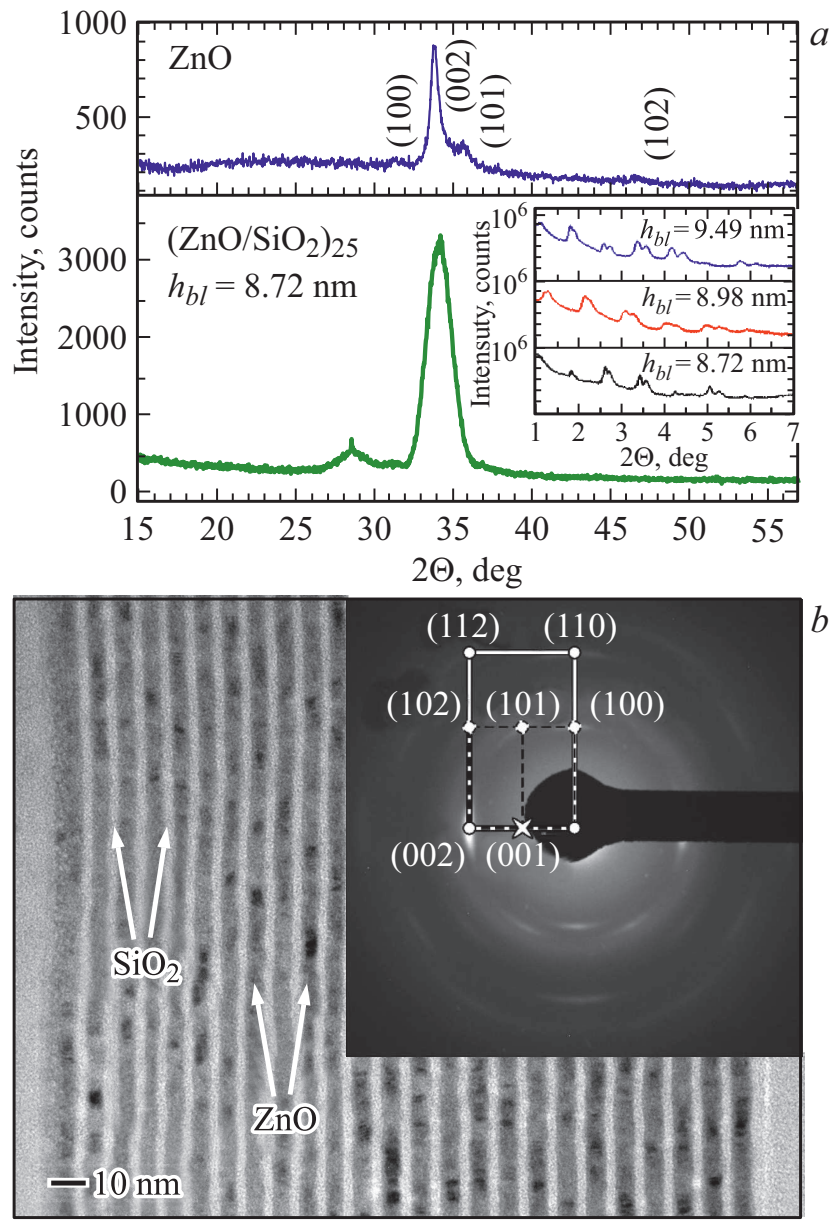

Рис. 1. $a-$ картины рентгеновской дифракции от тонкой пленки $\mathrm{ZnO}$ и гетероструктуры $\left(\mathrm{ZnO} / \mathrm{SiO}_{2}\right)_{25}$ с толщиной бислоя $h_{b l}=8.72$ нм (на вставке показаны картины рентгеновской дифракции гетероструктур $\left(\mathrm{ZnO} / \mathrm{SiO}_{2}\right)_{25}$ с различной толщиной бислоя, измеренные в области малых брегговских углов); $b-$ ПЭМ-микрофотография поперечного сечения и картина дифракции электронов от тонкой пленки $\left(\mathrm{ZnO} / \mathrm{SiO}_{2}\right)_{25}$ c $h_{b l}=7.76 \mathrm{HM}$.

\section{3. Экспериментальные результаты}

\section{1. Структура синтезированных пленок}

На рис. 1, $a$ приведены данные рентгеновской дифракции гетероструктур $\left(\mathrm{ZnO} / \mathrm{SiO}_{2}\right)_{25}$. В области углов $2 \Theta=30-40^{\circ}$ на картинах рентгеновской дифракции тонких пленок $\left(\mathrm{ZnO} / \mathrm{SiO}_{2}\right)_{25}$ имеется один широкий максимум (рис. $1, a)$, положение которого соответствует $2 \Theta \approx 34^{\circ}$ и не зависит от толщины бислоя. Положение и форма пика хорошо согласуются с положением рефлекса (002) $\mathrm{ZnO}$, полученного в аналогичных условиях (верхняя панель рис. $1, a)$ [12], что может свидетельствовать о том, что пленки $\left(\mathrm{ZnO} / \mathrm{SiO}_{2}\right)_{25}$ являются нанокристаллическими.

Наличие брегговских пиков в области малых углов указывает на формирование периодической слоистой структуры (см. вставку на рис. 1,a). Данный вывод подтверждается анализом микрофотографий ПЭМ поперечного сечения тонких пленок $\left(\mathrm{ZnO} / \mathrm{SiO}_{2}\right)_{25}$ (рис. $\left.1, b\right)$. Методом дифракции электронов были выявлены фазы аморфного $\mathrm{SiO}_{2}$, о чем свидетельствует наличие размытого гало на картинах электронной дифракции и кристаллического $\mathrm{ZnO}$, что проявляется в виде дугообразных рефлексов (см. вставку на рис. $1, b$ ). На основании анализа микрофотографий высокого разрешения и картин электронной дифракции можно сделать вывод, что структура прослоек $\mathrm{ZnO}$ является нанокристаллической. Анализ картин электронной дифракции показал, что в слоях присутствуют кристаллиты двух ориентаций, описываемых соотношением (100)[001] \| (110)[001], причем оси $\langle 001\rangle$ нанозерен $\mathrm{ZnO}$ ориентированы перпендикулярно плоскостям слоев многослойной структуры. Надо отметить, что расположение слоев относительно плоскости подложки имеют некоторую разориентацию, что проявляется на электронной дифракции как размытие рефлексов.

Таким образом, структура тонких пленок $\left(\mathrm{ZnO} / \mathrm{SiO}_{2}\right)_{25}$ представляет собой многослойную систему, в которой слои нанокристаллического $\mathrm{ZnO}$ разделены прослойками аморфного $\mathrm{SiO}_{2}$, причем $\mathrm{ZnO}$ в слоях имеет сильную текстуру с осью $\langle 001\rangle$.

\section{2. Электрические свойства синтезированных пленок}

На рис. 2 представлены результаты измерений электрического сопротивления синтезированной структуры от толщины бислоя $h_{b l}$. Измерения удельного электросопротивления при приложении электрического поля в направлении, параллельном плоскости слоев, показали, что проводимость пленок с увеличением толщины бислоя увеличивается, что является следствием небольшого уменьшения толщины прослойки $\mathrm{SiO}_{2}$ и увеличения толщины прослойки $\mathrm{ZnO}$.

Для установления основных механизмов проводимости в синтезированных пленках $\left(\mathrm{ZnO} / \mathrm{SiO}_{2}\right)_{25}$ были исследованы температурные зависимости электрического сопротивления в диапазоне температур $77-300 \mathrm{~K}$ (рис. $2, b$ ). Из рисунка видно, что зависимости $\rho \propto f(T)$ имеют отрицательный температурный коэффициент сопротивления (ТКС), что свойственно полупроводниковым материалам. С увеличением толщины бислоя $h_{b l}$ ТКС в исследуемом температурном диапазоне уменьшается.

Полученные экспериментальные зависимости (рис. $2, b)$ для пленок $\left(\mathrm{ZnO} / \mathrm{SiO}_{2}\right)_{25}$ были перестроены в координатах $\ln (\rho) \propto f\left(1 / T^{n}\right)$, где показатель $n$ принимал значения $1 / 4,1 / 2,1$, а также $\ln (\rho) \propto f(\ln T)$ и $(\rho) \propto f(\ln (T))$. Анализ экспериментальных данных рис. $2, b$ показал, что в области температур $77-250 \mathrm{~K}$ удельное электрическое сопротивление удовлетворительно описывается прямой линией в координатах 

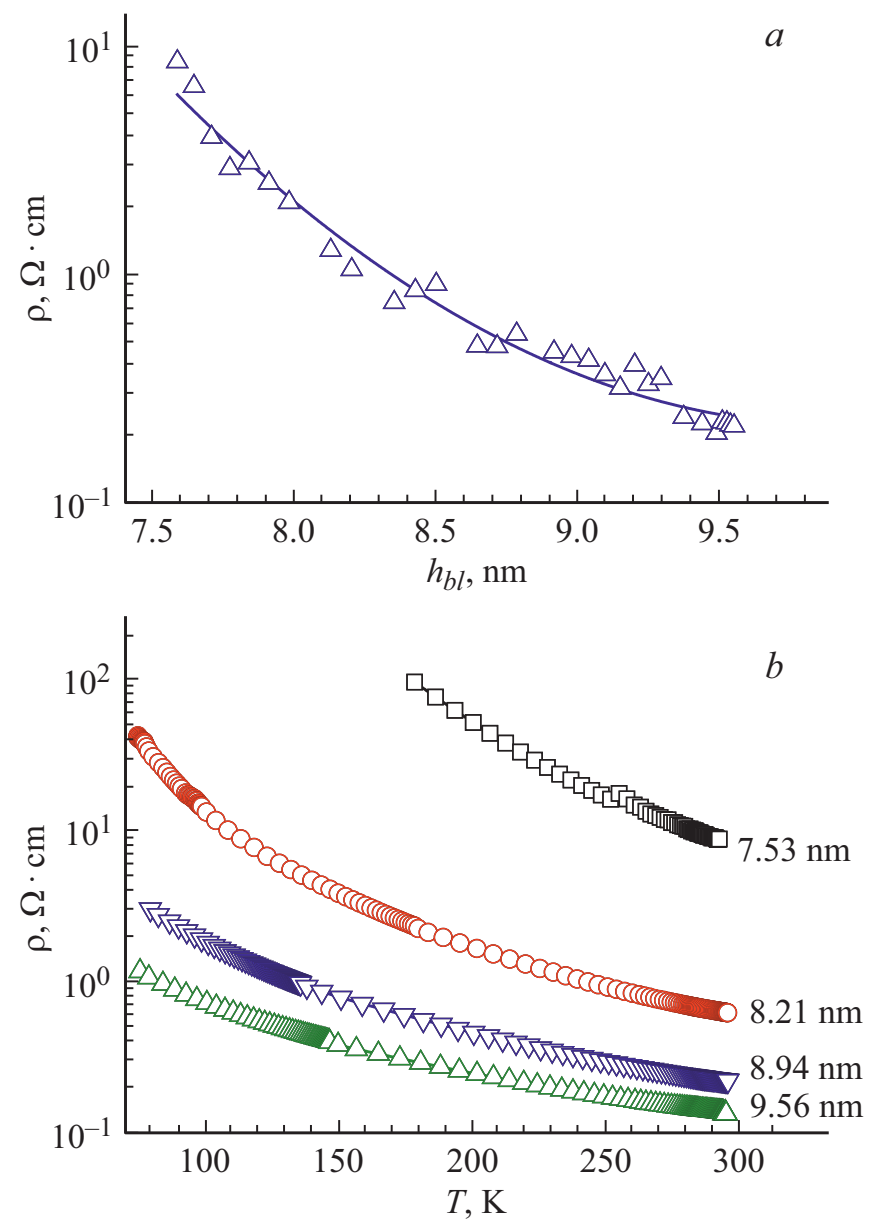

Рис. 2. Зависимости удельного электрического сопротивления $\rho$ тонкопленочных гетероструктур $\left(\mathrm{ZnO} / \mathrm{SiO}_{2}\right)_{25}$, измеренные при $T=300 \mathrm{~K}$, от толщины бислоя $h_{b l}(a)$ и от температуры $(b)$.

$\ln (\rho) \propto f\left(1 / T^{1 / 4}\right)$ (рис. $\left.3, a\right)$, что указывает на прыжковый механизм проводимости носителей заряда с переменной длиной прыжка по локализованным состояниям, лежащим в узкой полосе энергий вблизи уровня Ферми. Тогда, согласно [13], выражение для электрической проводимости имеет следующий вид:

$$
\sigma=e^{2} \cdot R^{2} v_{p h} \cdot g\left(E_{\mathrm{F}}\right) \exp \left(-\frac{B}{T}\right)^{1 / 4},
$$

где

$$
B=\frac{16}{a^{3} \cdot k_{\mathrm{B}} \cdot g\left(E_{\mathrm{F}}\right)},
$$

$e$ - заряд электрона, $R$ - среднее расстояние прыжка, $v_{p h}$ - фактор спектра фононов взаимодействия, $T-$ абсолютная температура, $g\left(E_{\mathrm{F}}\right)$ - плотность состояний на уровне Ферми, $a$ - радиус локализации волновой функции электрона, $k_{\mathrm{B}}$ - постоянная Больцмана.

Зная значения радиуса локализации электрона и величины $B$, по формуле (2) можно оценить значения эффективной плотности состояний на уровне Ферми $g\left(E_{\mathrm{F}}\right)$.
Принимая радиус локализации электрона равным эффективному боровскому радиусу,

$$
a_{\mathrm{B}}=\frac{\varepsilon_{0} \hbar}{m^{*} e^{2}},
$$

где $\varepsilon_{0}$ - статическая диэлектрическая проницаемость $\mathrm{ZnO}$, равная $8.5[14], m^{*} \sim m_{0}$ - эффективная масса электрона, $e-$ заряд электрона. Для $\mathrm{ZnO}$ расчет дает значение $a_{\mathrm{B}} \approx 0.46$ нм. Длину прыжка носителей заряда для разных составов пленок при температуре $200 \mathrm{~K}$ определим по формуле [13]

$$
R(T)=\frac{3}{8} a \cdot B^{1 / 4} T^{-1 / 4}
$$

Параметры тонких пленок $\left(\mathrm{ZnO} / \mathrm{SiO}_{2}\right)_{25}$, рассчитанные на основе модели прыжковой проводимости электронов с переменной длиной прыжка по локализован-
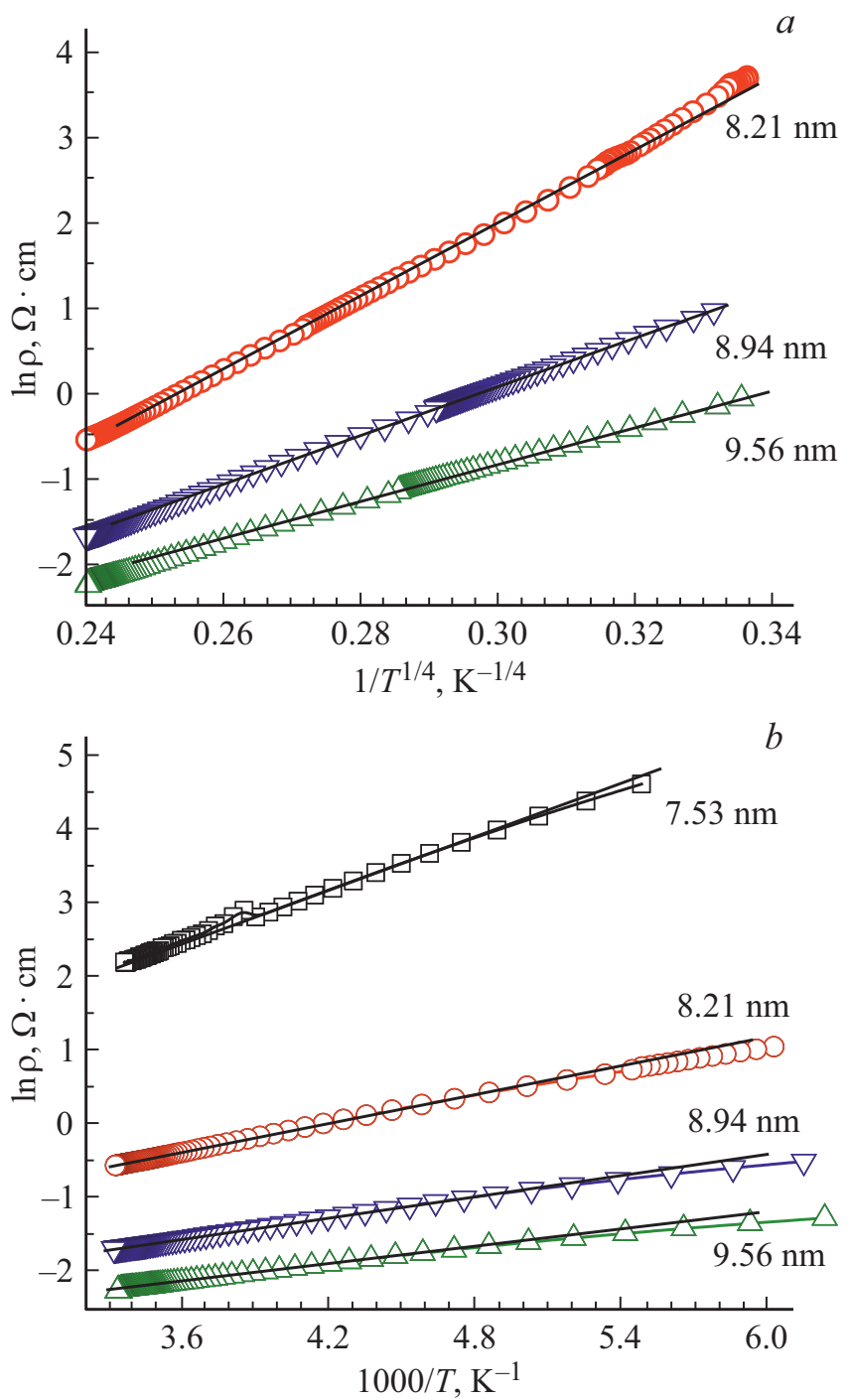

Рис. 3. Температурные зависимости удельного электрического сопротивления тонких пленок $\left(\mathrm{ZnO} / \mathrm{SiO}_{2}\right)_{25}$, представленные в координатах $\ln (\rho) \propto f\left(T^{-1 / 4}\right) \quad(a)$ и $\ln (\rho) \propto f(1 / T) \quad(b)$ (числами показаны значения толщины бислоя $h_{b l}$ ). 
Таблица 1. Параметры тонких пленок $\left(\mathrm{ZnO} / \mathrm{SiO}_{2}\right)_{25}$ с разной толщиной бислоя $h_{b l}$, вычисленные из модели прыжковой проводимости по локализованным состояниям вблизи уровня Ферми в температурном интервале от 80 до $250 \mathrm{~K}$

\begin{tabular}{c|c|c|c}
\hline$h_{\mathrm{bl}, \mathrm{HM}}$ & $B, \mathrm{~K}$ & $g\left(E_{\mathrm{F}}\right), э^{-1} \cdot \mathrm{cm}^{-3}$ & $R(200 \mathrm{~K}), \mathrm{HM}$ \\
\hline 8.21 & $(44.253)^{4}$ & $4.97 \cdot 10^{20}$ & 2.03 \\
8.94 & $(28.380)^{4}$ & $2.94 \cdot 10^{21}$ & 1.3 \\
9.56 & $(21.438)^{4}$ & $9.03 \cdot 10^{21}$ & 0.98
\end{tabular}

Таблица 2. Значения энергии активации электрической проводимости $W$ для тонких пленок $\left(\mathrm{ZnO} / \mathrm{SiO}_{2}\right)_{25}$ в диапазоне температур $250-300 \mathrm{~K}$

\begin{tabular}{c|c}
\hline$h_{b l}, \mathrm{HM}$ & $W,{ }^{\mathrm{BB}}$ \\
\hline 7.53 & $0.110 \pm 0.020$ \\
8.21 & $0.053 \pm 0.008$ \\
9.56 & $0.040 \pm 0.007$ \\
8.94 & $0.032 \pm 0.005$
\end{tabular}

ным состояниям из результатов обработки рис. 3, a приведены в табл. 1.

Результаты оценок, представленные в табл. 1, показывают, что с увеличением толщины бислоя плотность электронных состояний на уровне Ферми растет. Такой результат, вероятно, связан с тем, что по мере роста толщины бислоя толщина прослоек $\mathrm{ZnO}$, по которым главным образом осуществляется электроперенос, растет, а толщина прослоек $\mathrm{SiO}_{2}$ - падает. Другим важным результатом проведенных оценок является тот факт, что полученные значения средней длины прыжка в два-три раза меньше значений толщины монослоя $\mathrm{ZnO}$, что подтверждает справедливость применения формулы (1) для трехмерного прыжкового электропереноса. Следовательно, определяющий вклад в электрическую проводимость тонких пленок $\left(\mathrm{ZnO} / \mathrm{SiO}_{2}\right)_{25}$ вносят прослойки окиси цинка и интерфейс между слоями.

Экспериментальные зависимости электрического сопротивления в температурном интервале $250-300 \mathrm{~K}$ имеют линейные зависимости в координатах $\ln (\rho) \propto f(1000 / T)$ (рис. 3,b). Для описания температурных зависимостей электрической проводимости в этом интервале воспользуемся моделью термоактивированной проводимости, тогда, согласно [13], для электросопротивления должно выполняться равенство:

$$
\rho=\rho_{0} \exp \left(-\frac{W}{k_{\mathrm{B}} T}\right),
$$

где $W$ - энергия активации электрической проводимости. Применяя формулу (5), из рис. $3, b$ оценим значения энергии активации электрической проводимости. Результаты проведенных оценок приведены в табл. 2.

Полученные выше результаты $W$ соответствуют уровням межузельных атомов $\mathrm{Zn}$, являющихся мелкими донорами в пленках $\mathrm{ZnO}$ [15]. Таким образом, проводимость тонких пленок $\left(\mathrm{ZnO} / \mathrm{SiO}_{2}\right)_{25}$ при температурах, близких к комнатной, можно считать примесной, определяемой примесными уровнями прослоек окиси цинка.

\section{3. Влияние термообработки на структуру и электрические свойства пленок $\left(\mathrm{ZnO} / \mathrm{SiO}_{2}\right)_{25}$}

Для установления влияния термообработки на структуру и электрические свойства тонких пленок $\left(\mathrm{ZnO} / \mathrm{SiO}_{2}\right)_{25}$ были изучены температурные зависимости удельного электрического сопротивления в диапазоне температур от комнатной до $600^{\circ} \mathrm{C}$ в вакууме с давлением остаточных газов $P=5 \cdot 10^{-4}$ Торр. На рис. 4 показана температурная зависимость удельного электрического сопротивления тонких пленок $\left(\mathrm{ZnO} / \mathrm{SiO}_{2}\right)_{25}$ с толщиной бислоя $h_{b l}=7.65$ и $9.56 \mathrm{Hм}$ (кривые 1 и 2 соответственно) при нагреве до $600^{\circ} \mathrm{C}$ и последующем охлаждении. При нагреве выше комнатной температуры удельное электрическое сопротивление исследованных образцов уменьшается, достигая минимального значения при температуре $\sim 300^{\circ} \mathrm{C}$. Выше $\sim 300^{\circ} \mathrm{C}$ электрическое сопротивление образца начинает увеличиваться, при этом наиболее интенсивное увеличение электрического сопротивления наблюдается при $580^{\circ} \mathrm{C}$ для пленок с толщиной $h_{b l}=7.65 \mathrm{Hм}$ и при $530^{\circ} \mathrm{C}$ для образца с $h_{b l}=9.56$ нм. Зависимости $\rho(T)$, измеренные при охлаждении, имеют положительный ТКС, характерный для полупроводниковых материалов, при этом значение удельного электрического сопротивления тонких пленок $\left(\mathrm{ZnO} / \mathrm{SiO}_{2}\right)_{25}$ с толщиной бислоя $h_{b l}=9.56$ нм (кривая 2) стало больше значения удельного электрического сопротивления тонких пленок $\left(\mathrm{ZnO} / \mathrm{SiO}_{2}\right)_{25}$ с толщиной бислоя $h_{b l}=7.65$ нм (кривая 1$)$.

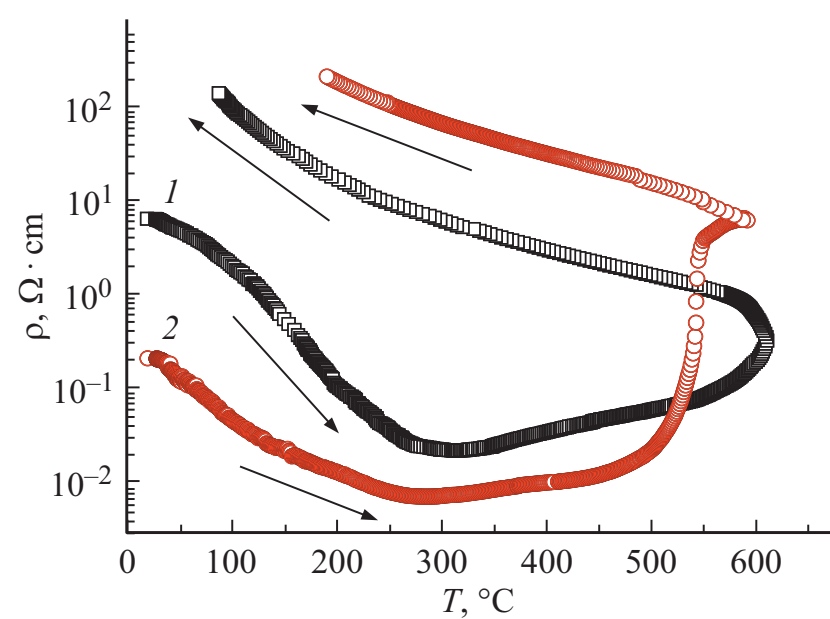

Рис. 4. Зависимости удельного электрического сопротивления тонких пленок $\left(\mathrm{ZnO} / \mathrm{SiO}_{2}\right)_{25}$ с различной толщиной бислоя $h_{b l}$ от температуры, измеренные в вакууме $P=5 \cdot 10^{-4}$ Tорр $\left(1-h_{b l}=7.65 \mathrm{HM}, 2-h_{b l}=9.56 \mathrm{HM}\right)$. 


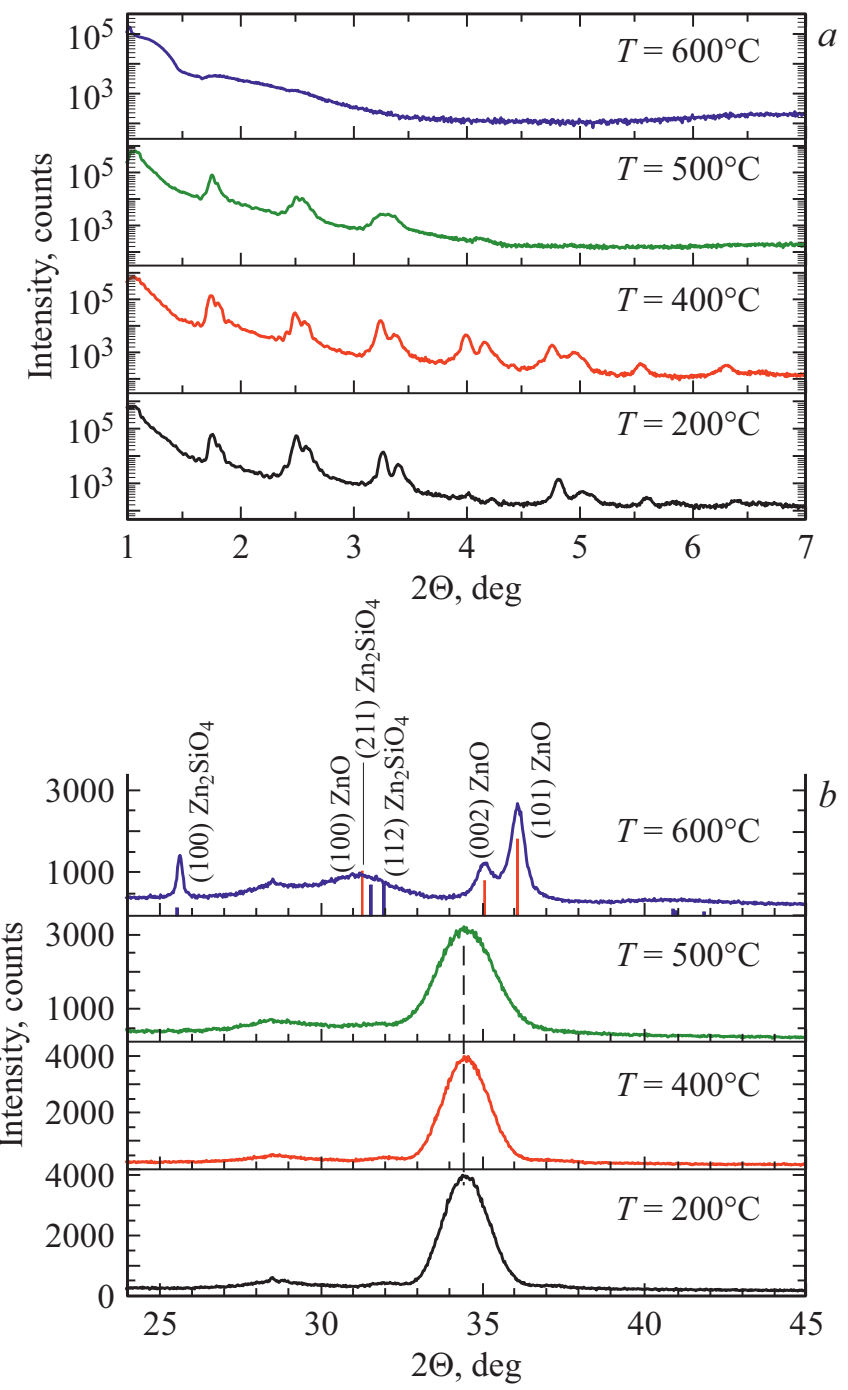

Рис. 5. Картины рентгеновской дифракции от тонкопленочных гетероструктур $\left(\mathrm{ZnO} / \mathrm{SiO}_{2}\right)_{25}$ с толщиной бислоя $h_{b l}=9.21 \mathrm{Hм}$ после термообработки в вакууме $P=5 \cdot 10^{-4}$ Торр при различных температурах в течение 30 мин.

Для объяснения описанных выше зависимостей $\rho(T)$ обратимся к анализу структуры и фазового состава тонких пленок $\left(\mathrm{ZnO} / \mathrm{SiO}_{2}\right)_{25}$, подвергнутых термообработке. На рис. 5 представлены картины рентгеновской дифракции многослойной структуры $\left(\mathrm{ZnO} / \mathrm{SiO}_{2}\right)_{25}$ с толщиной бислоя $h_{b l}=9.21$ нм после термообработки в вакууме $P=5 \cdot 10^{-4}$ Торр при различных температурах. Из представленных на рис. $5, a$ зависимостей $I(2 \Theta)$, измеренных в области малых брегговских углов $2 \Theta<7^{\circ}$, следует, что термообработка в вакууме при температурах, не превышающих $500^{\circ} \mathrm{C}$ включительно, не приводит к разрушению многослойной структуры, хотя рефлексы начинают немного уширяться, что можно интерпретировать как небольшое размытие границ раздела вследствие взаимной диффузии материалов слоев. Стабильность наноструктурного состояния после термообработки при температурах $T<500^{\circ} \mathrm{C}$ также подтверждается исследованиями в области углов $2 \Theta=24-45^{\circ}$. Оценка среднего размера кристаллитов $\mathrm{ZnO}$ проводилась по формуле Шеррера [16]:

$$
D=\frac{0.89 \lambda}{b \cos \Theta}
$$

где $\lambda-$ длина волны рентгеновского излучения (1.54 $\AA$ для $\mathrm{Cu} K_{\alpha}$-излучения), $b$ - ширина рефлекса на полувысоте, $\Theta-$ брегговский угол, $D-$ средний размер кристаллов. Результаты оценок показали, что термообработка при температуре $T=400^{\circ} \mathrm{C}$ приводит к незначительному увеличению размера кристаллитов с 5.6 до 5.7 нм по сравнению с пленками в исходном состоянии, однако увеличение температуры отжига до $T=500^{\circ} \mathrm{C}$ привело к уменьшению размера кристаллитов до $4.6 \mathrm{Hм}$, что является следствием взаимной диффузии материалов слоев и начала их химического взаимодействия. Следует отметить, что толщина монослоя $\mathrm{ZnO}$ в исследованном образце в исходном состоянии составляла $5.7 \mathrm{Hм}$, что полностью согласуется с проведенными оценками размеров кристаллитов.

Увеличение температуры термообработки до $600^{\circ} \mathrm{C}$ приводит к химическому взаимодействию слоев $\mathrm{ZnO}$ и $\mathrm{SiO}_{2}$ и появлению соединения $\mathrm{Zn}_{2} \mathrm{SiO}_{4}$ с тетрагональной структурой (пространственная группа $\mathrm{I}-42 d$ ) (верхняя панель рис. $5, b)$, а также к росту кристаллов $\mathrm{ZnO}$ до величины $\sim 19$ нм. Все это приводит к разрушению многослойной структуры, что подтверждается отсутствием рефлексов на картинах рентгеновской дифракции в области малых $2 \Theta$ (верхняя панель рис. 5,a). Появление непроводящей электрический ток фазы $\mathrm{Zn}_{2} \mathrm{SiO}_{4}$ проявляется в увеличении удельного электрического сопротивления тонких пленок $\left(\mathrm{ZnO} / \mathrm{SiO}_{2}\right)_{25}$ после термообработки при $T=600^{\circ} \mathrm{C}$.

\section{4. Заключение}

Методом ионно-лучевого распыления синтезированы многослойные тонкие пленки $\left(\mathrm{ZnO} / \mathrm{SiO}_{2}\right)_{25}$, состоящие из слоев нанокристаллического $\mathrm{ZnO}$ и прослоек аморфного $\mathrm{SiO}_{2}$. Толщина бислоя полученных структур изменялась в диапазоне от 6 до 10 нм. В интервале температур 77-300 K исследованы температурные зависимости электрического сопротивления синтезированных пленок. Установлено, что для тонких пленок $\left(\mathrm{ZnO} / \mathrm{SiO}_{2}\right)_{25}$ в исследованном диапазоне температур наблюдается последовательная смена доминирующего механизма проводимости от прыжкового с переменной длиной прыжка в узкой полосе энергий вблизи уровня Ферми при азотных температурах к примесной проводимости при температурах, близких к комнатной. По результатам исследования температурных зависимостей электрического сопротивления сделаны оценки эффективной плотности локализованных состояний на уровне Ферми и значений энергии активации примесных уровней. 
Исследовано влияние термической обработки в вакууме на структуру и электрические свойства синтезированных пленок. Установлено, что многослойная структура тонких пленок $\left(\mathrm{ZnO} / \mathrm{SiO}_{2}\right)_{25}$ является стабильной до температур $560-600^{\circ} \mathrm{C}$, при которых происходит химическое взаимодействие между слоями $\mathrm{ZnO}$ и $\mathrm{SiO}_{2}$, сопровождающееся разрушением многослойной структуры, появлением химического соединения $\mathrm{Zn}_{2} \mathrm{SiO}_{4}$ с тетрагональной структурой (пространственная группа $\mathrm{I}-42 d)$ и ростом кристаллов $\mathrm{ZnO}$.

\section{Благодарности}

Авторы выражают благодарность Центру коллективного пользования ФИЦ КНЦ СО РАН (г. Красноярск) за проведение электронно-микроскопических исследований образцов.

\section{Финансирование работы}

Работа выполнена при поддержке Министерства образования и науки РФ в рамках проектной части государственного задания (проект № 3.1867.2017/4.6).

\section{Конфликт интересов}

Авторы статьи заявляют, что у них нет конфликта интересов.

\section{Список литературы}

[1] D.C. Look, B. Claflin. MRS Symp. Proc., 829, b.8.6 (2005).

[2] Q. Xu, L. Hartmann, H. Schmidt, H. Hochmuth, M. Lorenz, R. Schmidt-Grund, C. Sturm, D. Spemann, M. Grundmann. Phys. Rev. B, 73 (20), 205342 (2006).

[3] T.S. Herng, S.P. Lau, C.S. Wei, L. Wang, B.C. Zhao, M.Tanemura, Y. Akaike. Appl. Phys. Lett., 95 (13), 133103 (2009).

[4] K. Toshio, H. Hideo. NPG Asia Materials, 2 (1), 15 (2010).

[5] H.M. Kim, C.H. Lee, B. Kim. J. Nanosci. Nanotechnol., 19 (3), 1790 (2019).

[6] Л.К. Марков, А.С. Павлюченко, И.П. Смирнова. ФТП, 53 (2), 181 (2019).

[7] S. Sanctis, J. Krausmann, C. Guhl. J. Mater. Chem. C, 6 (3), 464 (2018)

[8] S. Nam, J.H. Yang, S.H. Cho, J.H. Choi, O.S. Kwon, E.S. Park, S.J. Lee, K.I. Cho, J. Jang, C.S. Hwang. J. Mater. Chem. C, 4 (47), 11298 (2016).

[9] Ch.H. Ahn, S.H. Kim, Y.K. Kim, H.S. Lee, H.K. Cho. Thin Sol. Films, 584, 336 (2015).

[10] G. Cui, D. Han, J. Dong, Y. Cong, X. Zhang, H. Li, W. Yu, S. Zhang, X. Zhang, Yi. Wang. Japanese J. Appl. Phys., $56(4 s), 04 C G 03$ (2017).

[11] В.В. Рыльков, С.Н. Николаев, В.А. Демин, А.В. Емельянов, А.В. Ситников, К.Э. Никируй, В.А. Леванов, М.Ю.Пресняков, А.Н. Талденков, А.Л. Васильев, К.Ю. Черноглазов, А.С. Веденеев, Ю.Е. Калинин, А.Б. Грановский, В.В. Тугушев, А.С. Бугаев. ЖЭТФ, 153 (3), 424 (2018).
[12] O.V. Zhilova, S.Yu. Pankov, A.V. Sitnikov, Yu.E. Kalinin, I.V. Babkina. AIP Conf. Proc., 1886, 020054 (2017).

[13] Н.Ф. Мотт, Э.А. Дэвис. Электронные процессы в некристаллических веществах (М., Мир, 1982).

[14] N. Ashkenov, B.N. Mbenkum, C. Bundesmann, V. Riede, M. Lorenz, D. Spemann, E.M. Kaidashev, A. Kasic, M. Schubert, M. Grundmann. J. Appl. Phys., 93 (1), 126 (2003).

[15] F. Oba, A. Togo, I. Tanaka, J. Paier, G. Kresse. Phys. Rev. B, 77 (24), 245202 (2008).

[16] M. Maddahfar, M. Ramezani, S.M. Hosseinpour-Mashkani. Appl. Phys. A, 122 (8), 752 (2016).

Редактор Г.А. Оганесян

\section{The structure and electrical properties of thin films $\left(\mathrm{ZnO} / \mathrm{SiO}_{2}\right)_{25}$}

\author{
M.N. Volochaev' ${ }^{1}$, Yu.E. Kalinin ${ }^{2}$, M.A. Kashirin ${ }^{2}$, \\ V.A. Makagonov' ${ }^{2}$, S.Yu. Pankov², V.V. Bassarab ${ }^{2}$ \\ ${ }^{1}$ Kirensky Institute of Physics, \\ Siberian Branch Russian Academy of Siences, \\ 660036 Krasnoyarsk, Russia \\ 2 Voronezh State Technical University, \\ 394026 Voronezh, Russia
}

\begin{abstract}
Multilayer $\left(\mathrm{ZnO} / \mathrm{SiO}_{2}\right)_{25}$ thin films with a bilayer thickness of 6 to $10 \mathrm{~nm}$ has been synthesized in a single deposition process. The structure of the films consist of nanocrystalline $\mathrm{ZnO}$ layers and layers of amorphous $\mathrm{SiO}_{2}$. An analysis of the temperature dependences of the electrical resistivity, showed that a consistent change of the dominant conduction mechanism are realized in $\left(\mathrm{ZnO} / \mathrm{SiO}_{2}\right)_{25}$ thin films at temperatures $77-300 \mathrm{~K}$ : variable length hopping mechanism in a narrow energy band near the Fermi level at temperatures $77-250 \mathrm{~K}$ changed by the thermal activated impurity conductivity at close to room temperatures. The density of localized states and the activation energy of impurity conductivity has been estimated. The effect of heat treatment on the structure and electrical properties of the synthesized films has been investigated. It was found that the chemical interaction between the $\mathrm{ZnO}$ and $\mathrm{SiO}_{2}$ layers occurs at $580-600^{\circ} \mathrm{C}$. It accompanied by the destruction of the multilayer structure and the appearance of the chemical compound $\mathrm{Zn}_{2} \mathrm{SiO}_{4}$ with the tetragonal structure (I-42d space group).
\end{abstract}

